\title{
Symptoms without signs in outpatients attending ophthalmology clinics
}

\author{
A. G. KARSERAS AND A. H. CRISP \\ From the Department of Surgery, Welsh National School of Medicine, and St. George's Hospital \\ Medical School, London
}

SUMMARY Ophthalmic outpatients without physical signs have been shown, as a group, to be significantly more anxious and depressed than a control group. They also have a higher incidence of somatic complaints of a kind commonly made by patients with psychiatric 'disorder'. There was a higher incidence of past psychiatric history in the proband group, and they also gave a greater subjective assessment of recent conscious life stress.

It is evident that patients may present in a variety of general practice (Shepherd et al., 1966), outpatient, and inpatient (Crisp, 1967) clinical settings with symptoms which are usually eventually labelled 'psychiatric'. The commonest such settings are often said to be the general practitioner's surgery, female medical outpatient clinics, and gynaecological outpatient clinics. However, such patients may also come to other clinics, including surgical outpatient clinics (Davies, 1964), and they are fairly commonly seen in ophthalmic practice (Parinaud, 1906; Bahn, 1925; Bab, 1942; Schlaegel, 1957). In this paper we present an attempt to identify some additional psychological and social characteristics in such an ophthalmic outpatient population.

\section{Clinical material}

The proband population comprises 32 successive patients who attended the outpatient or casualty departments at Moorfield's Eye Hospital, High Holborn, London, and in whom the attending ophthalmologist could find no signs to account for the patients' symptoms. These patients were compared with a group of 230 subjects, a 1 in 10 random sample of other patients attending the same department, who will form the basis of a larger study by the first author.

\section{Method}

All patients were personally interviewed and a full ocular history and examination undertaken. Items

Address for reprints: Dr A. G. Karseras, Ophthalmic Department, St. Woolos Hospital, Newport, Gwent, Wales of information also recorded were age, sex, and social status, past ocular history, past psychiatric history, family history of eye disease, and family history of psychiatric disease.

In addition patients were scored on 2 analogue scales (simply straight lines $10 \mathrm{~cm}$ long on which they were invited to make a mark at an appropriate point) indicating the degree of severity of their main symptom and their view of the severity of total life stresses over the past 6 months respectively.

Finally, all patients completed the Middlesex Hospital Questionnaire (MHQ) (Crown and Crisp, 1966), a brief standardised self-rating inventory providing scores ( 0 to 16) on each of 6 scales covering between them a range of psychoneurotic disorders (anxiety scale, phobic scale, obsessional scale, somatic scale, depression scale, hysteria scale). Some of the 'norms' for these scales are known to be governed by age and sex factors and to a less extent by social class factors (Crisp and Priest, 1970, 1971).

The data concerning each patient were transcribed into a coded form. Statistical analysis was conducted by Mr Dunlop and Mr R. G. Newcombe, statisticians at the Chelsea College, London, and the Welsh National School of Medicine, respectively.

\section{Results}

AGE AND SEX

Among the proband group were 13 males $(40.6 \%)$ and 19 females $(59.4 \%)$. Their mean age was 41.9 years (males 37.9 years; females 46 years). Among the comparison group were 108 males $(47 \%)$ and 122 females $(53 \%)$. Their mean age was $48 \cdot 3$ years (males 48.1 years; females 47.9 years). The age 


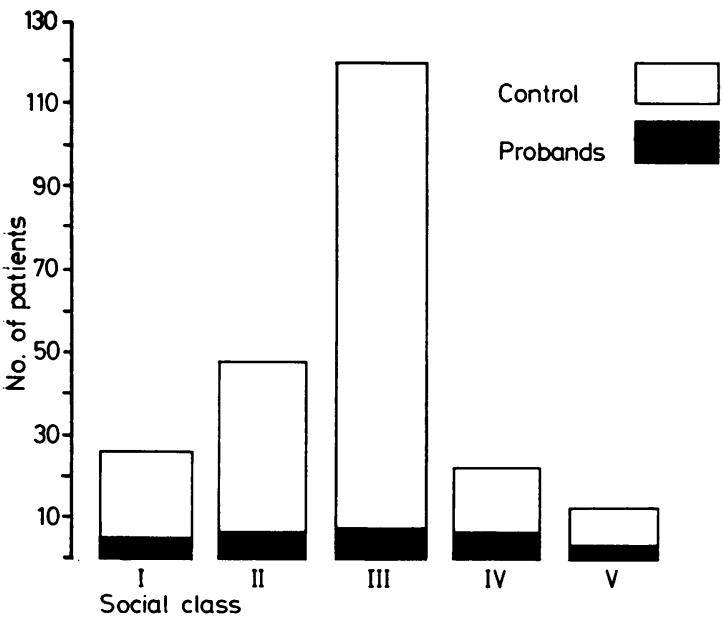

Fig. 1 Social class of probands and controls

and sex differences between the 2 groups are not significant.

\section{SOCIAL CLASS}

Distribution of the 2 groups by social class is displayed in Fig. 1. The distributions can be seen to be similar and are, in fact, not significantly different.

\section{CLINICAL FINDINGS}

The total symptoms complained of by the 32 subjects in the proband group are as follows: Eye pain, 10 cases; ocular discomfort, 10 cases; headache, 7 cases; visual loss, 5 cases; itching eyes, 4 cases; grittiness, 4 cases; other visual symptoms, 4 cases; floaters, 3 cases; photopsiae, 2 cases; gross exaggerated symptoms, 1 case; fortuitous presentation, 1 case (follow-up patient with presentation symptoms).

Thus there were 51 symptoms in the 32 patients. Only 1 patient was judged to have presented his complaint in a histrionic and extravagant manner. There were no significant differences in the frequency of any of the above symptoms between the proband and comparison groups except for the category of 'other visual symptoms' (4 patients), which was relatively commoner in the proband group $(\mathrm{P}<0.01)$.

There was no significant difference between the 2 groups in respect of past ocular history as reported by them, concerning both themselves and their immediate families.

A family history of 'nervous disorder' (defined as an illness requiring admission to psychiatric hospital or an illness obviously treated as such over a period of time by the general practitioner) was not significantly different at the $5 \%$ level in the proband group and the comparison group. It was not thought safe to assume that no relationship existed between the 2 groups regarding this factor (Table 1).

Comparison between the proband and control groups regarding past psychoneurotic history showed a highly significant preponderance in the proband group $(P<0.001)$ (Table 2$)$ in terms of episodes of such illness.

The degree of severity of symptoms as noted on the analogue scale was not different between the 2 groups at the $5 \%$ level.

The degree of subjective assessment of total life stress over the past 6 months was significantly different for the 2 groups. The mean score for the proband group was $6 \cdot 1 \pm 2.7$ and that for the comparison group $4.7 \pm 2.9(\mathrm{P}<0.01)$.

Rating of psychoneurotic status: Table 3 shows that the proband group scored significantly higher

Table 1 Presence or absence of psychiatric family history in probands and controls

\begin{tabular}{lcc}
\hline & No. of probands & No. of controls \\
\hline $\begin{array}{l}\text { With psychiatric family } \\
\text { history }\end{array}$ & 9 & 44 \\
$\begin{array}{l}\text { Without psychiatric family } \\
\text { history }\end{array}$ & 15 & 181 \\
$\begin{array}{l}\text { Total } \\
\text { Total }\end{array}$ & 24 & 225 \\
\hline
\end{tabular}

Table 2

\begin{tabular}{llll}
\hline & $\begin{array}{l}\text { No past } \\
\text { psychoneurotic } \\
\text { history }\end{array}$ & $\begin{array}{l}\text { Frequent visits } \\
\text { to doctors }\end{array}$ & $\begin{array}{l}\text { History of } \\
\text { drugs or } \\
\text { hospital for } \\
\text { neurosis }\end{array}$ \\
\hline Controls & 161 & 13 & 55 \\
Probands & 13 & 0 & 18 \\
\hline
\end{tabular}

Table 3 Means and standard deviations of subscale scores and total scores on $M H Q$ of proband and comparison groups

\begin{tabular}{lllll}
\hline & $\begin{array}{l}\text { Probands } \\
n=32 \\
\text { Mean } \pm S D\end{array}$ & $\begin{array}{l}\text { Comparison group } \\
n=231 \\
\text { Mean } \pm S D\end{array}$ & $t$ and significance \\
\hline A* & $8.66 \pm 3.50$ & $5.23 \pm 3.55$ & 5.19 & P $<0.001$ \\
P & $4.50 \pm 3.94$ & $3.91 \pm 2.28$ & 0.82 & NS \\
O & $8.03 \pm 3.19$ & $7.73 \pm 3.22$ & 0.50 & NS \\
S & $7.12 \pm 3.95$ & $4.65 \pm 3.22$ & 3.99 & P $<0.001$ \\
D & $6.44 \pm 3.20$ & $4.03 \pm 2.76$ & 4.06 & P $<0.001$ \\
H & $4.59 \pm 3.40$ & $4.22 \pm 3.42$ & 0.58 & NS \\
Total & $39.34 \pm 14.20$ & $29.75 \pm 12.86$ & 3.62 & P $<0.001$ \\
\hline
\end{tabular}

* Letters signify scales on MHQ (see column headings in Table 4) 
than the comparison group on the anxiety scale, the somatic scale, the depression scale, and also on the overall score.

Fig. 2 shows that the MHQ 'profile' of the proband group was similar to that of other groups of psychiatric outpatients comparable to the probands in respect of age and sex distribution. Moreover, this profile is strikingly and significantly different $(\mathrm{P}<0.001)$ from that shown by a normal population of similar age and sex distribution.

\section{Discussion}

We have shown that a group of patients attending an ophthalmic outpatient department with 'eye' complaints and found to be without ocular or other physical signs have certain psychopathological characteristics. As a group they are significantly more anxious and depressed than groups of other ophthalmic outpatients. Furthermore, they are about as depressed and anxious as a nonpsychotic psychiatric outpatient population in so far as the MHQ measures these characteristics. They also score high on the somatic scale of the MHQ, which is perhaps not surprising, since this scale is intended to identify somatic complaints of a kind commonly made by patients with 'psychiatric disorder' and without gross physical disease. However, the patients in our proband group were in most other respects not different from all other ophthalmic patients attending the outpatient department. Moreover, they did not appear to complain unduly.

Loss of vision was not a common complaint among the proband group, although it is often described as a symptom which can have psychological origins, usually, it is thought, through socalled hysterical conversion mechanisms. In addition, the proband groups were not significantly different

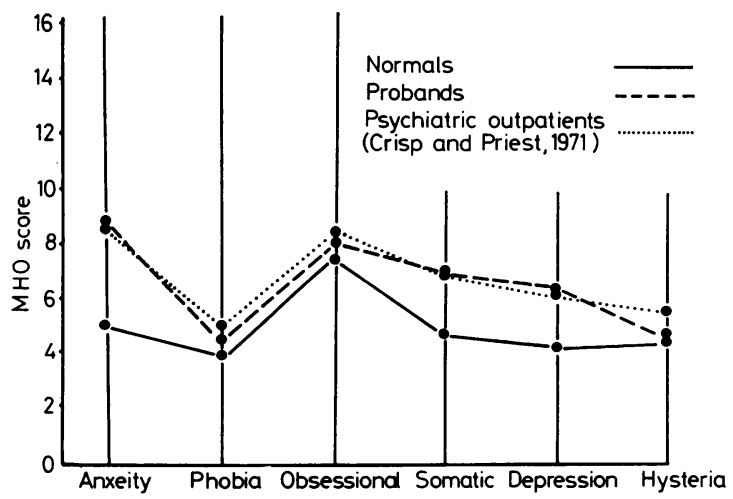

Fig. $2 M H Q$ 'profile' of probands compared with that of other groups
Table 4 Visual loss and $M H Q$ scores

\begin{tabular}{|c|c|c|c|c|c|c|c|}
\hline Patient & Anxiety & Phobia & $\begin{array}{l}\text { Obses- } \\
\text { sional }\end{array}$ & Somatic & $\begin{array}{l}\text { Depres- } \\
\text { sion }\end{array}$ & Hysteria & Total \\
\hline 1 & 12 & 0 & 9 & 9 & 16 & 4 & 60 \\
\hline 2 & 10 & 3 & 9 & 12 & 5 & 0 & 39 \\
\hline 3 & 8 & 5 & 10 & 15 & 8 & 3 & 49 \\
\hline 4 & 15 & 5 & 12 & 15 & 14 & 11 & 82 \\
\hline 5 & 6 & 6 & 5 & 3 & 5 & 3 & 28 \\
\hline
\end{tabular}

on the hysteria scale of the MHQ, although it must be stated that this scale is the least well substantiated of the 6 scales. Of the 5 patients complaining of visual loss 4 showed very high total psychoneurotic scores; only 1 showed a high hysteria score, and this patient had a total score of 82 (Table 4).

Classical hysterical conversion symptoms are not associated with evidently high levels of anxiety or depression. However, Parinaud (1906) states that 'hysteria may be observed in the same patient simultaneously with another neurosis or with organic disease'. Davenport (1944) described severely disturbed soldiers with psychogenic blindness under the increased stresses of war, who were having 'night terrors' even after recovery of their sight. Michaelson (1943) likewise found 'no clear dividing line between hysteria and other psychoneuroses' and that the clinical picture may show a hysterical reaction superimposed on an anxiety state.

The proband group were also characterised by the high frequency with which they reported previous psychiatric illness in themselves and by the high assessment they made of the degree of their life stresses during the recent past (this self-assessment was borne out by the evidence obtained in the clinical interview). These factors are, of course, features of patients with psychiatric illness, although clearly not exclusively so.

It must be borne in mind that a proportion of the comparison group will also be patients without physical signs, and a preliminary head count suggests that this proportion is about $15 \%$. This factor, together with the observation that 'neuroticism' is, statistically speaking (Sainsbury, 1960), a fairly widespread factor among hospital patients, enhances if anything the significance of the above findings in respect of the proband group.

We thank Mr R. G. Newcombe and Dr K. A. Johns, of the Department of Medical Statistics at the Welsh National School of Medicine, for help with the statistics and computer programing, respectively, and also Mr I. Dunlop, formerly of the Chelsea Computer Centre. 


\section{References}

Bab, W. (1942). Psychologic problems in ophthalmologic diagnosis. American Journal of Ophthalmology, 25, 326-329.

Bahn, C. A. (1925). In discussion of W. T. Davies. Southern Medical Journal, 18, 300.

Crisp, A. H. (1967). The role of the psychiatrist in the general hospital. Postgraduate Medical Journal, 44, 267276.

Crisp, A. H., and Priest, R. G. (1970). Nature of complaint in relation to social class. Psychotherapy and Psychosomatics, 18, 216-225.

Crisp, A. H., and Priest, R. G. (1971). Psychoneurotic profiles in middle age. British Journal of Psychiatry, 119, 385-392.

Crown, S., and Crisp, A. H. (1966). A short clinical diagnostic self-rating scale for psychoneurotic patients. The Middlesex Hospital Questionnaire (MHQ). British Journal of Psychiatry, 112, 917-923.
Davenport, R. C. (1944). Discussion on ocular psychoneurotics. Transactions of the Ophthalmic Society, LXIV, 24-36.

Davies, B. (1964). Psychiatric illness at general hospital clinics. Postgraduate Medical Journal, 40, 15-18.

Michaelson, I. C. (1943). Ocular manifestations of neuroses commonly found among soldiers. British Medical Journal, 2, 538-541.

Parinaud, M. (1906). System of Diseases of the Eye Vol. 4, p. 827. Edited by W. F. Norris and C. A. Oliver. Lippincott: Philadelphia.

Sainsbury, P. (1960). Psychosomatic disorders and neurosis in outpatients attending a general hospital. Journal of Psychosomatic Research, 4, 261-273.

Schaegel, T. F. (1957). Psychosomatic Ophthalmology, p. 3. Williams \& Wilkins: Baltimore.

Shepherd, M., Cooper, B., Brown, A. C., and Kaeton, G. (1966). Psychiatric Illness in General Practice. Oxford University Press: Oxford. 